\title{
O PATRIMÔNIO URBANO E ARQUITETÔNICO DA PEQUENA CIDADE DO OESTE PAULISTA: A EXPERIÊNCIA DO LUGAR E O PROJETO DE INTERVENÇÃO
}

Hélio Hirao, Matheus A. S. Chaparim

Universidade Estadual Paulista - UNESP, Departamento de Planejamento, Urbanismo e Ambiente, Presidente Prudente, SP. E-mail: hirao@fct.unesp.br

\section{RESUMO}

$\mathrm{O}$ artigo discute uma experiência de ensino desenvolvida com alunos do quarto ano de arquitetura e urbanismo da Universidade Estadual Paulista "Júlio de Mesquita Filho", Campus de Presidente Prudente na disciplina Técnicas Retrospectivas, em 2016. Os procedimentos metodológicos utilizaram instrumentos perceptivos para subsidiar propostas de intervenção sobre o patrimônio urbano e arquitetônico de uma pequena cidade do interior do oeste paulista, Indiana. Para isso, fez o reconhecimento do lugar examinando as sensações das atmosferas percebidas através das derivas realizadas no centro histórico. As hipóteses de intervenção revelaram preocupações em qualificar os espaços livres abertos e públicos como ponto fundamental para a preservação do patrimônio com intervenções que valorizam o potencial das formas, dos significados e de ativação do lugar, coerente com o cotidiano das pessoas, proporcionando espaços de apropriação e permanência, considerando assim, ações não apenas no objeto, mas nas relações que se estabelece entre ele, a comunidade e a cidade.

Palavras-chave: técnicas retrospectivas, percepção, intervenção projetual.

\section{THE URBAN AND ARCHITECTURAL HERITAGE OF THE SMALL CITY OF WEST PAULISTA: THE EXPERIENCE OF THE PLACE AND THE PROJECT OF INTERVENTION}

\begin{abstract}
The article discusses a teaching experience developed with students of the fourth year of architecture and urbanism of the Paulista State University "Júlio de Mesquita Filho", Campus of Presidente Prudente in the discipline Retrospective Techniques, in 2016. The methodological procedures used perceptive instruments to subsidize proposals of Intervention on the urban and architectural heritage of a small city in the interior of western São Paulo, Indiana. To do this, he made the recognition of the place by examining the sensations of the atmospheres perceived through the drifts in the historic center. The hypothesis of intervention revealed concerns about qualifying open and public spaces as fundamental for the preservation of heritage with interventions that value the potential of forms, meanings and reactivation of the place, consistent with the daily life of the people, providing spaces of appropriation and Permanence, considering thus, actions not only in the object, but in the relations established between him, the community and the city.

Keywords: retrospective techniques, perception, project of intervention.
\end{abstract}

\section{INTRODUÇÃO}

A prática do ensino de graduação desenvolvida na disciplina Técnicas Retrospectivas no 4․ ano do curso de arquitetura e urbanismo da Universidade Estadual Paulista "Júlio de Mesquita Filho"- Campus de Presidente Prudente, em 2016, trouxe elementos para análises e reflexões sobre as formas de identificação e reconhecimento do patrimônio urbano e arquitetônico de pequenas cidades paulistas visando a construção de hipóteses para a definição de ações que busquem a sua preservação.

\section{METODOLOGIA}

A disciplina utilizou instrumentos perceptivos nos procedimentos metodológicos na condução do processo de concepção de possibilidades de intervenções sobre as 
preexistências edificadas. Esses procedimentos tiveram como referência os estudos de autores como Solà-Morales (2002), Juhani Pallasmaa (2006), Peter Zumthor (2006), Josep Montaner (2008), Francesco Careri (2013) e Guy-Ernest Debord (1958).

A pequena cidade de Indiana foi a escolhida para o desenvolvimento da disciplina. Protagonista do processo inicial de ocupação do oeste paulista, não acompanhou o crescimento econômico de Presidente Prudente, mas ainda apresenta os registros materiais do núcleo inicial de ocupação.

Derivas ao centro histórico de Indiana foram feitas buscando a percepção do cotidiano considerando sua ambiência e atmosfera ${ }^{1}$ como subsídios para produzir "cartogramas sensitivos", registros psicogeográficos, instrumentos para contribuir na elaboração das propostas de intervenção.

Desta forma, o caminhar pela cidade sem um roteiro preestabelecido, conduzidos pelas solicitações das ambiências e atmosferas, proporcionou que anotassem e descrevessem as sensações e experiências percebidas, assim como as conversas informais com as pessoas encontradas ao acaso possibilitou a imersão no cotidiano de Indiana.

De maneira complementar, uma pesquisa sobre o processo histórico e cultural da formação do núcleo urbano, expresso através de diagramas, produziu uma segunda camada de conhecimentos sobre as características da cidade.

Consequência do processo de colonização e avanço dos trilhos da estrada de ferro no oeste do estado de São Paulo, que procuravam novas terras férteis para o cultivo do café, amendoim e algodão abandonando as anteriores utilizadas à exaustão, os núcleos urbanos foram criados com características particulares que ao intervir nas qualidades físicas como topografia, vegetação e cursos d'água, construíram infraestruturas, vias de circulação edificações e mobiliários, como também, geraram apropriação socioespacial por seus moradores, atribuindo significados e estruturando fortes identidades regionais e locais.

No caso específico de Indiana, a implantação da estação ferroviária e avenidas demarcando o limite da área urbana com a rural,

\footnotetext{
${ }^{1}$ Conceito cunhado por Peter Zumthor em seu livro Atmosferas: Entornos Arquitetônicos - As coisas que me rodeiam. O autor diz: "A atmosfera comunica com a nossa percepção emocional, isto é, a percepção que funciona de forma instintiva e que o ser humano possui para sobreviver" (ZUMTHOR, 2006).
}

num contexto de extensas áreas "vazias" sem construções, permitiu que o núcleo urbano se concretizasse com a implantação dos equipamentos públicos como a praça, a prefeitura, a escola, a igreja, o fórum, entre outros, junto com o comércio e habitações em seu entorno, dentro de um traçado quadriculado em forma de tabuleiro de xadrez.

Por outro lado, verifica-se a produção de uma arquitetura singela e característica, ao construírem equipamentos públicos e privados, identificando os locais pelo uso e apropriação socioespacial.

No decorrer dos anos, adequações aos novos usos provocaram intervenções sobre as preexistências edificadas, nem sempre considerando a preservação das características iniciais, provocando descaracterizações, demolições e abandonos. Contudo, muitos deles permanecem e constituem-se em testemunhos materiais significativos da arquitetura e urbanismos produzidos pelas gerações anteriores.

Ao se relacionar a arquitetura com o território, observa-se que as cidades são constituídas por inúmeras formas arquitetônicas reveladoras, entre elas, de história, cultura, tecnologia e valores estéticos (YAZIGI, 2002), modificadas ao longo do tempo pelos novos usos e apropriações socioespaciais que produzem adequações e novas estruturas urbanas e arquitetônicas, justapondo às antigas preexistências construídas, proporcionando uma diversidade de ambiências e atmosferas das cidades e que precisam ser valorizadas.

Desta forma, integraram a camada da percepção com a evolução urbana da pequena cidade para sintetizar a essência da ambiência e atmosfera como subsídios para conceberem hipóteses de intervenções visando à preservação do patrimônio identificado e reconhecido. Assim, estruturaram propostas hipotéticas de salvaguarda desses espaços carregados de significações cujas preexistências construídas ainda se constituem de importantes referências históricas e culturais da cidade.

\section{RESULTADOS - DA DERIVA À PERCEPÇÃO}

Para identificar e reconhecer o patrimônio urbano e arquitetônico de Indiana os alunos foram para o trabalho de campo. Inicialmente, ao chegarem de ônibus na antiga Estação Ferroviária, caminharam pelo centro histórico com o objetivo de realizar derivas (DEBORD 2003, CARERI, 2013). 
Sem nenhum roteiro prévio, orientados apenas pelas solicitações das ambiências e atmosferas do local, percorreram as ruas com atenção para as sensações que lhes eram suscitadas. No decorrer do percurso diversas sinergias ocorreram, por vezes conversas rápidas com pessoas encontradas ao acaso, permitindo uma imersão no cotidiano da pequena cidade.

Essa primeira deriva proporcionou subsídios suficientes para construírem um esboço de cartogramas individuais como registros das sensações percebidas (Figura 1-2). Um seminário que ocorreu na aula seguinte debateu esses produtos, possibilitando verificar as similaridades, diversidades complementaridades, o que levou a compreender a necessidade de realizar novas derivas visando leituras das atmosferas. ]

Figuras 1-2. Cartogramas Sensitivos
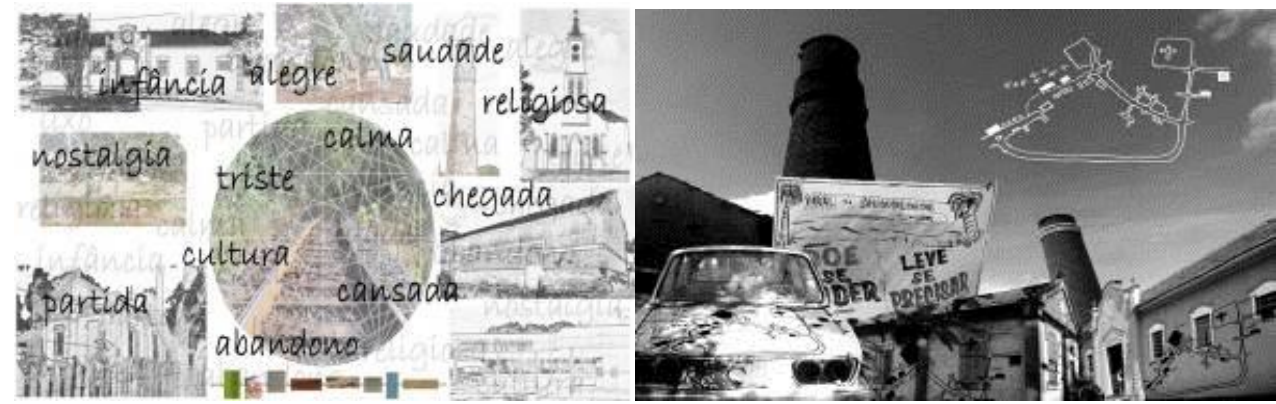

Fonte: Arquivo da disciplina, 2017.

As questões relacionadas com o calor e tradição do local, como a produção da cerâmica (principal atividade econômica da cidade), foram percebidas nos trabalhos apresentados.

Em grupos de cinco alunos, estes esboços foram desenvolvidos até chegarem a uma síntese gráfica (Figura 3), como um "código de barras", por meio de linguagens não verbais (desenhos, colagens, pequenos filmes, etc.).

Figura 3. A deriva expressa como cartograma sensitivo

Fonte: Arquivo disciplina, 2016.

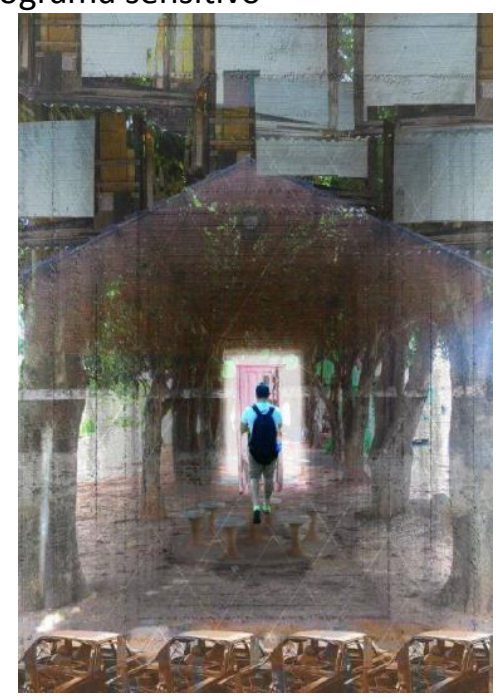

O passo seguinte foi realizar uma interpretação crítica da história e evolução urbana de Indiana através de revisões bibliográficas e iconográficas. Nesta etapa foram produzidos diagramas voltados para salientar os conteúdos significativos da cidade ao longo do tempo. (Figura 4-5). 
Figuras 4-5. Diagramas da evolução urbana de Indiana

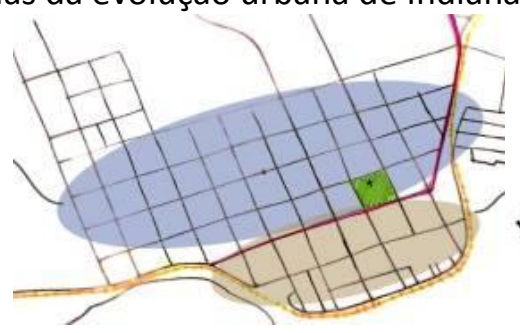

Fonte: Arquivo Disciplina, 2017.

A justificativa para este esforço metodológico de levar os conceitos teóricos para as experiências práticas e, em seguida, serem desenvolvidos como produtos gráficos, fundamenta-se na importância da linguagem gráfica como ferramenta e instrumento do arquiteto e urbanista para espacializar seu pensamento e compreender o lugar estudado.

\section{DISCUSSÃO - DA PERCEPÇÃO À INTERVENÇÃO}

As propostas de possíveis intervenções foram produtos da interação das relações entre as camadas das percepções sensitivas das ambiências e atmosferas e os diagramas do processo histórico da cidade.

Nesse procedimento metodológico, muitas vezes, os alunos foram levados a realizar novas derivas, assim como conversar com moradores e gestores destes espaços. Os lugares a serem trabalhados foram percebidos com fortes significados para seus usuários e tornaramse determinantes no momento de decisões projetuais das intervenções concebidas, possuindo um ponto em comum: o uso dos espaços públicos abertos para a valorização do patrimônio preexistente.

As intervenções desenvolvidas escolheram três recortes espaciais no contexto do centro histórico de Indiana. O primeiro tratou do conjunto ferroviário que engloba um galpão, a estação e uma habitação ferroviária. O segundo

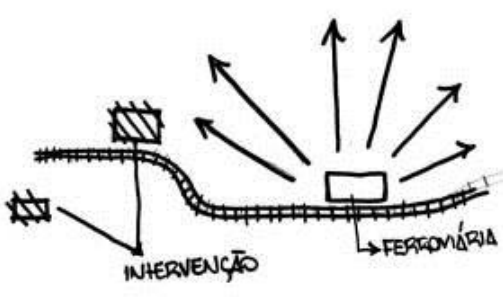

enfocou a praça da matriz e suas quadras adjacentes. E o último trabalhou prédios históricos, como os presentes na rua principal de comércio e uma olaria, hoje atividade econômica predominante.

Quanto ao primeiro recorte (conjunto ferroviário), as propostas do "grupo 1" partiram de cartogramas de energia percebida para definir os lugares das permanências das pessoas, qualificando os espaços abertos e a relação do edifício com seu entorno para valorização do patrimônio edificado da estação ferroviária e do galpão existente. Uma intervenção que respeita os usos preexistentes, deixando a população escolher o que poderia ser feito (Figura 8).

0 "grupo 2", por sua vez, percebeu nas conversas com os moradores uma divisão social de partes da cidade, entre o núcleo mais antigo onde há moradores com idades mais avançadas e os bairros mais novos com os mais jovens. Assim, propuseram possibilidades de integração através das áreas livres abertas para o convívio de todos, pensando também na contemplação do patrimônio urbano e arquitetônico, protagonista do lugar (Figura 7).

De outro modo, o "grupo 3" abordou o projeto com o ponto de vista do planejamento urbano estratégico, propondo zoneamentos e loteamentos, mas sem deixar de privilegiar os espaços abertos para apropriação das pessoas, qualificando o entorno para garantir a sobrevivência da obra e a participação da comunidade (Figura 8). 
Figuras 6-8. Intervenções sobre Conjunto Ferroviário. Grupo 1 (esquerda), grupo 2 (meio) e grupo 3 (direita)
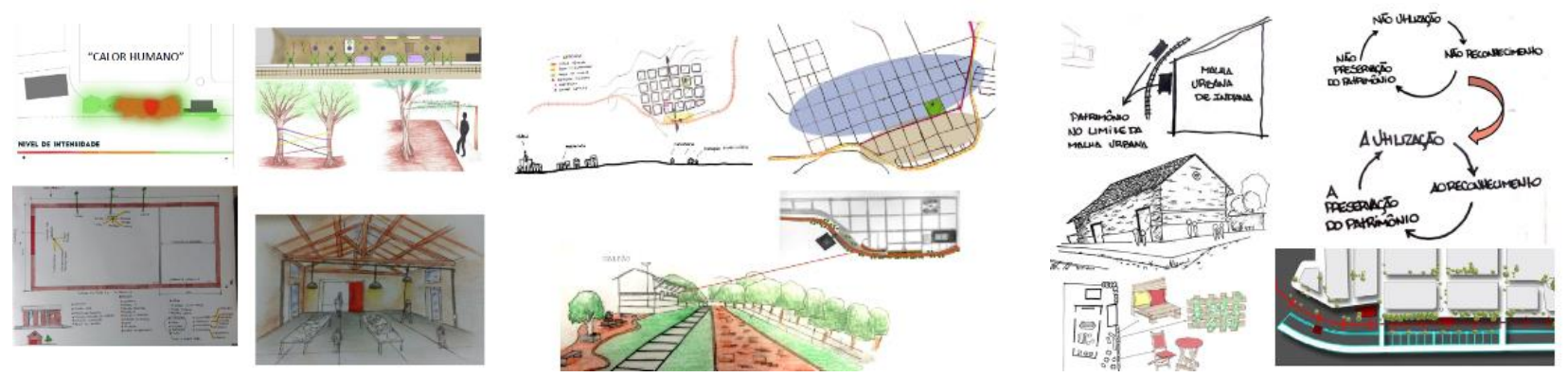

Fonte: Arquivo da disciplina, 2017.

Os grupos que concentram suas intervenções sobre o recorte da praça central possuíram em comum o fato de fugirem das intervenções físicas nos edifícios. Entretanto, cada um priorizou um tipo de relação do local com a cidade.

O "grupo 4" visou resgatar o simbolismo da praça, percebida apenas como um lugar de passagem e não mais de permanência. Assim, o projeto propôs dar mais unidade para o local, fragmentada em sua composição e usos, sem interferir no edifício da igreja existente (Figura 9).
O espaço sem uso do posto de gasolina fechado em frente à praça central e próximo do antigo cinema que existia, foi o alvo do projeto de intervenção do "grupo 5", que buscou resgatar a antiga relação marcante que havia entre o cinema e a praça. A intervenção estimula a apropriação da área aberta atrás do posto, sem intervir em sua estrutura, por meio de projeções que convidam as pessoas para o local e remetem ao antigo uso do cinema (Figura 10).

Figuras 9 e 10. Intervenções sobre a Praça Central. Grupo 4 (esquerda) e grupo 5 (direita)
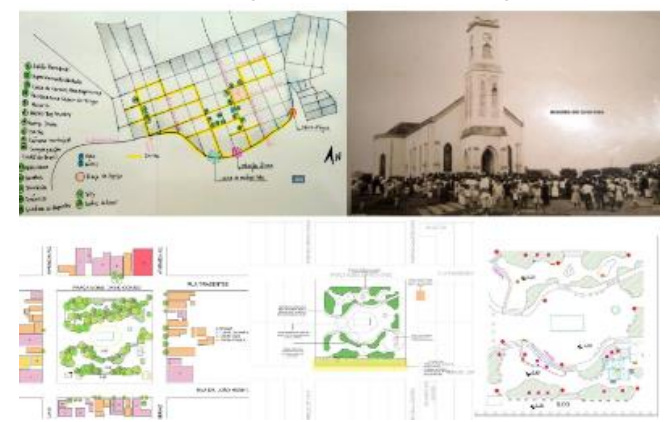

Fonte: Arquivo da disciplina, 2017.

Quanto ao último recorte, a proposta sugerida pelo "grupo 6" teve como foco a rua principal do comércio. Durante as derivas notaram que as características arquitetônicas das fachadas dos edifícios, modestas, não eram respeitadas pelos anúncios publicitários. Assim, tomando como referência a lei "Cidade Limpa" da cidade de São Paulo, buscaram valorizar os aspectos arquitetônicos com uma série de alternativas à publicidade das lojas (Figura 13).
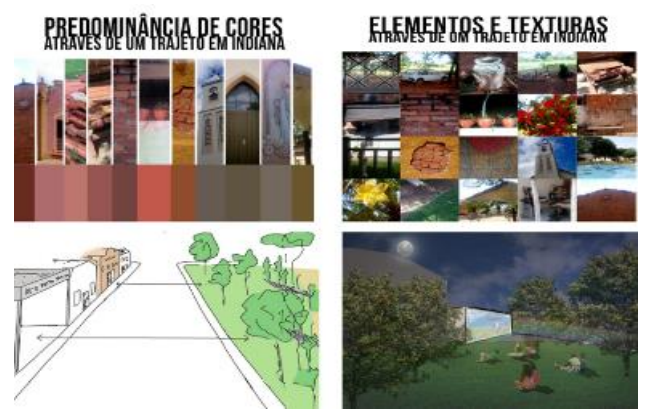

Por fim, também houve a preocupação com aspectos do patrimônio cultural da cidade, como pelo "grupo 7" com intervenção sobre uma antiga olaria. A partir de um estudo do programa funcional da produção cerâmica, e das sensações afloradas pelas derivas, conceberam um circuito convidativo para os visitantes ao inserirem a atmosfera existente, valorizando o processo de produção (Figura 14). 
Figuras 13 e 14. Intervenções sobre prédios históricos. Grupo 6 (esquerda) e grupo 7 (direita).

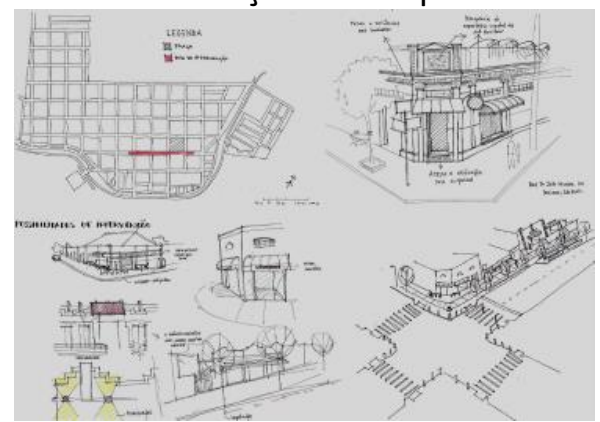

Fonte: Arquivo da disciplina, 2017.

\section{CONCLUSÕES - DO PROCEDIMENTO} METODOLÓGICO, O ENCAMINHAMENTO

A prática da deriva (CARERI, 2013; DEBORD, 2003) atenta às solicitações das ambiências e atmosferas do centro histórico de Indiana, proporcionou uma experiência fenomenológica, por meio da vivência e experiência corporal (PALLASMAA, 2006).

Esse procedimento metodológico encaminhou propostas de intervenções que revelaram a preocupação com tratamento dos espaços livres, abertos e públicos, do entorno das edificações consideradas de interesse de preservação pelo seu valor histórico e cultural. Buscaram priorizar os lugares de vivências como importantes para cidade e como suportes materiais da memória coletiva da cidade.

0 uso da linguagem gráfica pelos cartogramas sensitivos e diagramas possibilitou a espacialização dos conceitos estudados, como expressão das experiências sensoriais das derivas, constituindo-se como um produto deste procedimento metodológico.

Entende-se que $\mathrm{o}$ ato de projetar em preexistências edificadas não trata apenas de se pensar o objeto, mas também compreender suas relações com as ambiências e os tempos das cidades. Assim, as propostas de projeto se pautaram em sua maioria na valorização do espaço público como necessária para valorização do patrimônio urbano e arquitetônico.

Desta forma, foi possível verificar o potencial de transformação dos espaços abertos com valor histórico e cultural, mesmo em pequenas cidades com pouca dinâmica econômica. Através do seu reconhecimento como experiência urbana, demonstra, ainda que preliminarmente, a forte relação entre a forma arquitetônica e o modo como ela é experienciada, para alimentar o processo de
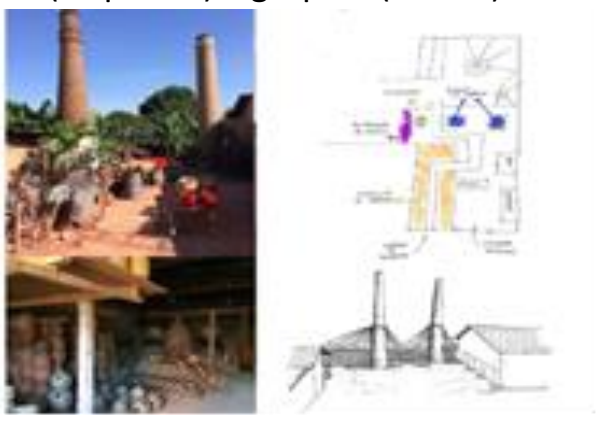

concepção projetual sobre os ambientes preexistentes.

Deste modo, percebe-se a importância destas possibilidades de intervenções se tornarem atmosferas com significados para a existência ou presença humana (SOLÀ-MORALES, 2002) para sua permanência no espaço urbano revigorar um sentido de lugar compartilhado da cidade.

\section{REFERÊNCIAS}

CARERI, F. Walkscapes: o caminhar como prática estética. São Paulo: G. Gili, 2013.

DEBORD, G. Teoria da deriva. In: JACQUES, P.O. (Org). Apologia da deriva. Rio de Janeiro: Casa da Palavra, 2003.

MONTANER, J. M. Sistemas arquitectónicos contemporáneos. Barcelona: G. Gili, 2008.

PALLASMAA, J. A geometria do sentimento: um olhar sobre a arquitetura. In: NESBITT, K. (Org). Uma nova agenda para a arquitetura: antologia teórica 1965-1995. São Paulo: Cosac Naify, 2006.

SOLÀ-MORALES, I. Terrain Vague. In: Territórios. Barcelona: G. Gili, 2002.

YAZIGI, E. (Org.). Turismo: espaço, paisagem e cultura. São Paulo: Hucitec, 2002.

ZUMTHOR, P. Atmosferas: entornos arquitectônicos, as coisas que me rodeiam. Barcelona: Gustavo Gili, 2006.

Recebido para publicação em 09/08/2017

Revisado em 18/09/2017

Aceito em 25/09/2017 